УДК 502.53(574.2)

ОЦЕНКА ПРОСТРАНСТВЕННО-ВРЕМЕННОЙ ИЗМЕНЧИВОСТИ ТЕМПЕРАТУРНОГО РЕЖИМА И ОСАДКОВ ЗА МНОГОЛЕТНИЙ ПЕРИОД НА ТЕРРИТОРИИ СЕВЕРНОГО КАЗАХСТАНА

\author{
${ }_{1,2}^{1,}$ Кусаинова А.А., ${ }^{2,3}$ Мезенцева О.В. \\ ${ }^{1}$ Карагандинский технический университет, Караганда, е-mail: aimarh@mail.ru; \\ ${ }^{2}$ ФББОУ ВО «Омский государственный педагогический университет», \\ Омск, е-mail: mezolga@yandex.ru; \\ ${ }^{3}$ ФББОУ ВО «Омский государственный аграрный университет», Омск
}

\begin{abstract}
Тенденции последних десятилетий на территории Северного Казахстана характеризуют различную повторяемость увлажнённых и засушливых лет. В статье исследовано пространственно-временная изменчивость температуры воздуха и количества осадков за многолетний период с использованием данных элементов климата метеостанций «Благовещенка» и «Атбасар», расположенных в Северном Казахстане. Определены абсолютная и относительная повторяемость значений среднемесячной температуры воздуха и среднемесячного количества осадков в июле за 60-летний временной интервал с 1961 по 2020 г., разделенный на 2 периода (I и II). На метеостанции «Благовещенка» по сравнению с I периодом во II периоде отмечается увеличение повторяемости на $6 \%$ часто встречающихся значений среднемесячной температурь воздуха июля в пределах $18-19,9^{\circ} \mathrm{C}$. На метеостанции «Атбасар» по сравнению с I периодом во II периоде значение часто повторяемой среднемесячной температуры воздуха июля снизилось на $1-2{ }^{\circ} \mathrm{C}$ от многолетней нормы. Во II периоде по сравнению с I периодом на метеостанции «Благовещенка» наблюдается уменьшение повторяемости засушливых лет на 7\%, увеличение увлажнённых лет на $3 \%$, а на метеостанции «Атбасар» наблюдается уменьшение повторяемости засушливых лет на $23 \%$ и увеличение увлажнённых лет на 10\%. Динамика среднемесячного количества осадков июля за I период (1961-1990 гг.) показала тенденцию роста количества осадков на исследуемых метеостанциях (больше на метеостанции «Атбасар»), за II период (1991-2020 гг.) - уменьшение среднемесячного количества осадков июля на обеих метеостанциях. Составленный прогноз на 2021 г. характеризует снижение осадков июля.
\end{abstract}

Ключевые слова: температура воздуха, количество осадков, изменчивость, динамика, повторяемость

\title{
ASSESSMENT OF SPATIO-TEMPORAL VARIABILITY OF TEMPERATURE REGIME AND PRECIPITATION OVER THE LONG-TERM PERIOD IN THE TERRITORY OF NORTHERN KAZAKHSTAN
}

\author{
${ }^{1,2}$ Kusainova A.A., ${ }^{2,3}$ Mezentseva O.V. \\ ${ }^{1}$ Karaganda Technical University, Karaganda,e-mail: aimarh@mail.ru; \\ 2Omsk State Pedagogical University, Omsk, e-mail: mezolga@yandex.ru; \\ ${ }^{3}$ Omsk State Agrarian University, Omsk
}

\begin{abstract}
Trends of recent decades in the territory of Northern Kazakhstan characterize the different recurrence of humidified and arid years. The article investigated the spatio-temporal variability of air temperature and rainfall over a long period using these climate elements of the weather stations Blagoveshchenka and Atbasar, located in Northern Kazakhstan. Absolute and relative repeatability of the values of the average monthly air temperature and the average monthly rainfall in July for the 60-year time interval from 1961 to 2020 . divided into 2-periods (I and II). At the Blagoveshchenka weather station, compared with the I period in the II period, there is an increase in repeatability by $6 \%$ of the often encountered values of the average monthly air temperature of July within $18-19.9^{\circ} \mathrm{C}$. At the Atbasar weather station, compared with the I period in the II period, the value of the often repeated monthly average air temperature in July decreased by $1-2{ }^{\circ} \mathrm{C}$ from the long-term norm. In the II period, compared with the I period, at the Blagoveshchenka weather station, there is a decrease in the recurrence of dry years by $7 \%$, an increase in humidified years by $3 \%$, and at the Atbasar weather station, there is a decrease in the recurrence of dry years by $23 \%$ and an increase in humidified years by $10 \%$. The dynamics of the average monthly rainfall of July for the I-th period (1961-1990) showed a tendency to increase the amount of precipitation in the weather stations under study (more in the weather station Atbasar), for the II-th period (1991-2020) - a decrease in the average monthly rainfall of July at both weather stations. The forecast for 2021 shows a decrease in precipitation in July.
\end{abstract}

Keywords: Air temperature, precipitation, variability, dynamics, repeatability

Исследование пространственно-временной изменчивости температуры воздуха и количества осадков и их соотношения позволяет определить благоприятность климатических условий территорий. В Северном Казахстане изменчивость температурного режима и количества осадков последних десятилетий характеризуется тенденцией пе- риодической повторяемости увлажнённых и засушливых лет.

Цель исследования: в данной работе дана оценка пространственно-временной изменчивости температурного режима и осадков за многолетний период на территории Северного Казахстана на примере метеостанций «Благовещенка» и «Атбасар». 


\section{Материалы и методы исследования}

Для оценки пространственно-временной изменчивости температурного режима и количества осадков на территории Северного Казахстана использованы непрерывные данные за июль, разделенные на 2 периода (I и II), за 60-летний временной интервал с 1961 по 2020 г., полученные на метеостанциях «Благовещенка» (СевероКазахстанская область) и «Атбасар» (Акмолинская область) [1;2].

Используя метод статистического анализа, находим абсолютную повторяемость или частоту $m_{i}$ (число случаев), то есть число, показывающее, сколько раз значение конкретной градации выборки температуры воздуха и количества осадков встречается в общей совокупности $n$ в каждом из периодов. А также вычисляется относительная повторяемость или частота $p_{i}$ соответствующего интервала (градации) к сумме всех частот $n$.

\section{Результаты исследования и их обсуждение}

По анализу метеорологических данных, приведенных в табл. 1 и на рис. 1, установлена абсолютная и относительная повторяемость среднемесячной температуры воздуха в июле для метеостанции «Благовещенка», которая показывает, что в течение I периода (1961-1990 гг.) количество лет со среднемесячной температурой воздуха $16-17,9{ }^{\circ} \mathrm{C}$ составляет 3 , с температурой воздуха $18-19,9^{\circ} \mathrm{C}$ составляет 13 , с температурой воздуха $20-21,9^{\circ} \mathrm{C}-10$, с температурой воздуха $22-23,9^{\circ} \mathrm{C}-3$, с температурой воздуха $24-25,9^{\circ} \mathrm{C}-1$. Исходя из этого определена наиболее высокая относитель- ная повторяемость значений - 44 \% в пределах среднемесячной температуры воздуха $18-19,9^{\circ} \mathrm{C}$. Кумулятивная повторяемость $87 \%$ составляет среднемесячная температура воздуха июля в пределах $16-21,9^{\circ} \mathrm{C}$. Многолетняя норма среднемесячной температуры воздуха июля на метеостанции «Благовещенка» составляет $+19,8^{\circ} \mathrm{C}$. Как видно в табл. 1 и на рис. 1, относительная повторяемость значений среднемесячной температуры воздуха июля в течение I периода (1961-1990 гг.) в пределах нормы в данной местности равняется $44 \%$, то есть наибольшую повторяемость имеет значение температуры воздуха, соответствующее многолетней норме [3].

В течение II периода (1991-2020 гг.) количество лет со среднемесячной температурой воздуха $14-15,9^{\circ} \mathrm{C}$ составляет 1 , со среднемесячной температурой воздуха $16-17,9^{\circ} \mathrm{C}-3$, с температурой воздуха $18-19,9^{\circ} \mathrm{C}-15$, с температурой воздуха 20 $21,9^{\circ} \mathrm{C}-8$, количество лет с температурой воздуха $22-23,9^{\circ} \mathrm{C}-3$.

Исходя из этого определена наиболее высокая относительная повторяемость значений - $50 \%$, в пределах среднемесячной температуры воздуха $18-19,9^{\circ} \mathrm{C}$. Кумулятивная повторяемость - 90\% составляет среднемесячная температура воздуха июля в пределах $14-21,9^{\circ} \mathrm{C}$. Относительная повторяемость значений среднемесячной температуры воздуха июля в течение II периода (1991-2020 гг.) в пределах нормы в данной местности равняется $50 \%$, то есть наибольшую повторяемость в метеостанции «Благовещенка» имеет значение, соответствующее многолетней норме температуры воздуха июля $+19,8^{\circ} \mathrm{C}$.

Таблица 1

Абсолютная и относительная повторяемость значений среднемесячной температуры воздуха и среднемесячного количества осадков июля с 1961 по 2020 г. на метеостанции «Благовещенка»

\begin{tabular}{|c|c|c|c|c|c|c|c|c|c|c|c|}
\hline \multicolumn{6}{|c|}{ І период (1961-1990 гг.) } & \multicolumn{6}{|c|}{ II период (1991-2020 гг.) } \\
\hline \multicolumn{3}{|c|}{ t воздуха, ${ }^{\circ} \mathrm{C}$} & \multicolumn{3}{|c|}{ кол-во осадков, мм } & \multicolumn{3}{|c|}{ t воздуха, ${ }^{\circ} \mathrm{C}$} & \multicolumn{3}{|c|}{ кол-во осадков, мм } \\
\hline $\mathrm{t}$ & $\mathrm{m}_{\mathrm{i}}$ & $\mathrm{p}_{\mathrm{i}}, \%$ & $\mathrm{X}$ & $\mathrm{m}_{\mathrm{i}}$ & $\mathrm{p}_{\mathrm{i}}, \%$ & $\mathrm{t}$ & $\mathrm{m}_{\mathrm{i}}$ & $\mathrm{p}_{\mathrm{i}}, \%$ & $X$ & $\mathrm{~m}_{\mathrm{i}}$ & $\mathrm{p}_{\mathrm{i}}, \%$ \\
\hline $14-15,9$ & 0 & 0 & $0-19$ & 3 & 10 & $14-15,9$ & 1 & 3 & $0-19$ & 1 & 3 \\
\hline $16-17,9$ & 3 & 10 & $20-39$ & 6 & 20 & $16-17,9$ & 3 & 10 & $20-39$ & 6 & 20 \\
\hline $18-19,9$ & 13 & 44 & $40-59$ & 7 & 24 & $18-19,9$ & 15 & 50 & $40-59$ & 8 & 28 \\
\hline $20-21,9$ & 10 & 33 & $60-79$ & 6 & 20 & $20-21,9$ & 8 & 27 & $60-79$ & 6 & 20 \\
\hline $22-23,9$ & 3 & 10 & $80-99$ & 6 & 20 & $22-23,9$ & 3 & 10 & $80-99$ & 2 & 6 \\
\hline \multirow[t]{3}{*}{$24-25,9$} & \multirow[t]{3}{*}{1} & \multirow[t]{3}{*}{3} & 100-119 & 1 & 3 & \multirow[t]{3}{*}{$24-25,9$} & \multirow[t]{3}{*}{0} & \multirow[t]{3}{*}{0} & $100-119$ & 5 & 17 \\
\hline & & & $120-139$ & 1 & 3 & & & & $120-139$ & 1 & 3 \\
\hline & & & $140 \ldots 210$ & 0 & 0 & & & & $140 \ldots 210$ & 1 & 3 \\
\hline
\end{tabular}




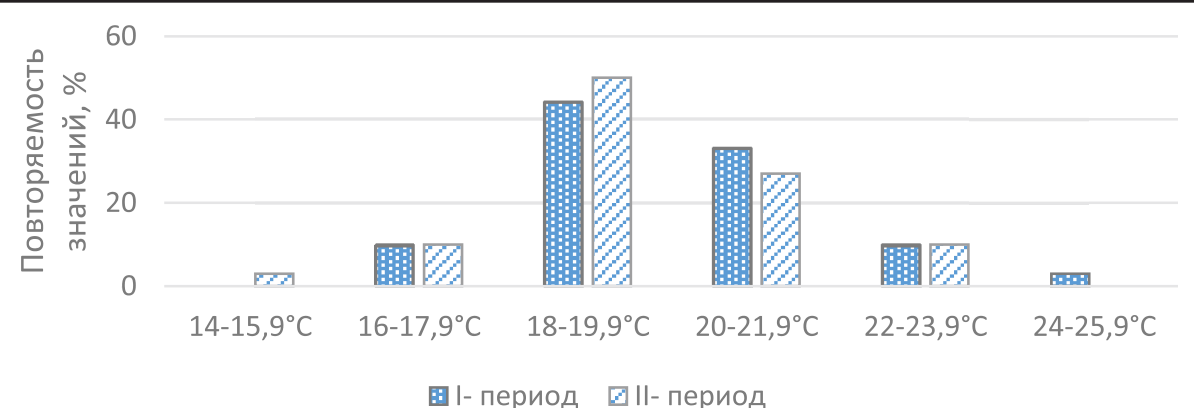

Рис. 1. Относительная повторяемость значений среднемесячной температуры воздуха июля на метеостанциии «Благовещуенка» за I (1961-1990 г2.) и II (1991-2020 г2.) периодь

По сравнению с I периодом во II периоде повторяемость среднемесячной температуры воздуха $18-19,9^{\circ} \mathrm{C}$ увеличилась на $6 \%$, а повторяемость среднемесячной температуры воздуха $20-21,9^{\circ} \mathrm{C}$ уменьшилась на $6 \%$ (рис. 1$)$.

По данным, представленным в табл. 2 и на рис. 2 , абсолютная и относительная повторяемость среднемесячной температуры воздуха в июле для метеостанции «Атбасар» характеризуется следующим образом. В течение I периода (1961-1990 гг.) количество лет со среднемесячной температурой воздуха $16-17,9{ }^{\circ} \mathrm{C}$ составляет 1 , с температурой воздуха $18-19,9^{\circ} \mathrm{C}-10$, с температурой воздуха $20-21,9^{\circ} \mathrm{C}-14$, с температурой воздуха $22-23,9^{\circ} \mathrm{C}-5$.

Исходя из этого определена наиболее высокая относительная повторяемость значений $-47 \%$ в пределах среднемесячной температуры воздуха $20-21,9^{\circ} \mathrm{C}$. Кумулятивная повторяемость - $83 \%$ составляет среднемесячная температура воздуха июля в пределах $16-21,9^{\circ} \mathrm{C}$. Многолетняя норма среднемесячной температуры воздуха июля на метеостанции «Атбасар» составляет $+20,2^{\circ} \mathrm{C}$. Относительная повторяемость значений среднемесячной температуры воздуха июля в течение I периода (1961-1990 гг.) в пределах нормы в данной местности равняется 47\%, то есть наибольшую повторяемость имеет значение температуры воздуха, соответствующее многолетней норме.

В течение II периода (1991-2020 гг.) количество лет со среднемесячной температурой воздуха $16-17,9^{\circ} \mathrm{C}$ составляет 3 , с температурой воздуха $18-19,9^{\circ} \mathrm{C}$ составляет 13 , с температурой воздуха $20-21,9^{\circ} \mathrm{C}-11$, с температурой воздуха $22-23,9^{\circ} \mathrm{C}-2$, с температурой воздуха $24-25,9^{\circ} \mathrm{C}-1$.

Исходя из этого определена наиболее высокая относительная повторяемость значений $-43 \%$ в пределах среднемесячной температуры воздуха $18-19,9^{\circ} \mathrm{C}$. Кумулятивная повторяемость - $90 \%$ составляет среднемесячная температура воздуха июля в пределах $16-21,9^{\circ} \mathrm{C}$. Относительная повторяемость значений среднемесячной температуры воздуха июля в течение II периода (1991-2020 гг.) в пределах нормы $\left(+20,2^{\circ} \mathrm{C}\right)$ в данной местности равняется $37 \%$, наибольшую повторяемость на метеостанции «Атбасар» имеет значение $18-19,9{ }^{\circ} \mathrm{C}$, которое на $1-2{ }^{\circ} \mathrm{C}$ ниже многолетней нормы температуры воздуха июля.

По сравнению с I периодом во II периоде относительная повторяемость среднемесячной температуры воздуха $16-17,9^{\circ} \mathrm{C}$ увеличилась на 7\%, температуры воздуха 18 $19,9^{\circ} \mathrm{C}$ увеличилась на $10 \%$, температуры воздуха $20-21,9^{\circ} \mathrm{C}$ и $22-23,9^{\circ} \mathrm{C}$ уменьшились на $10 \%$ (рис. 2).

Многолетняя норма среднемесячного количества осадков на метеостанции «Благовещенка» в июле составляет 56 мм. Как видно на рис. 3, а, в течение I периода (1961-1990 гг.) повторяемость значений среднемесячного количества осадков ниже нормы, в пределах 0-39 мм, встречается в 30\% исследованных лет; повторяемость значений среднемесячного количества осадков 40-59 мм, в пределах нормы, отмечается в $24 \%$; осадки, превышающие норму, в пределах 60-120 мм, выпали в 46\% исследованных лет.

В течение II периода (1991-2020 гг.) повторяемость значений среднемесячного количества осадков ниже нормы, в пределах 0-39 мм, встречается в 23\% исследованных лет, повторяемость значений среднемесячного количества осадков 40-59 мм, в пределах нормы, отмечается в $28 \%$ исследованных лет. Во II периоде осадки, превышающие норму, в пределах 60-210 мм, выпали в 49\% исследованных лет (рис. 3 , а). Многолетняя норма среднемесячного количества осадков 
на метеостанции «Атбасар» в июле составляет 47 мм. Как видно на рис. 3, б, в течение I периода (1961-1990 гг.) повторяемость значений среднемесячного количества осадков ниже нормы, в пределах 0-39 мм, встречается в $60 \%$ исследованных лет, по- вторяемость значений среднемесячного количества осадков 40-59 мм, в пределах нормы, отмечается в $17 \%$ исследованных лет. B I периоде осадки, превышающие норму, в пределах 60-159 мм, выпали в 23 \% исследованных лет.

Таблица 2

Абсолютная и относительная повторяемость значений среднемесячной температуры воздуха и среднемесячного количества осадков июля с 1961 по 2020 г. на метеостанции «Атбасар»

\begin{tabular}{|c|c|c|c|c|c|c|c|c|c|c|c|}
\hline \multicolumn{6}{|c|}{ І период (1961-1990 гг.) } & \multicolumn{6}{|c|}{ II период (1991-2020 гг.) } \\
\hline \multicolumn{3}{|c|}{ t воздуха, ${ }^{\circ} \mathrm{C}$} & \multicolumn{3}{|c|}{ кол-во осадков, мм } & \multicolumn{3}{|c|}{ t воздуха, ${ }^{\circ} \mathrm{C}$} & \multicolumn{3}{|c|}{ кол-во осадков, мм } \\
\hline $\mathrm{t}$ & $\mathrm{m}_{\mathrm{i}}$ & $\mathrm{p}_{\mathrm{i}}, \%$ & $\mathrm{X}$ & $\mathrm{m}_{\mathrm{i}}$ & $\mathrm{p}_{\mathrm{i}}, \%$ & $\mathrm{t}$ & $\mathrm{m}_{\mathrm{i}}$ & $\mathrm{p}_{\mathrm{i}}, \%$ & $\mathrm{X}$ & $\mathrm{m}_{\mathrm{i}}$ & $\mathrm{p}_{\mathrm{i}}, \%$ \\
\hline $14-15,9$ & 0 & 0 & $0-19$ & 3 & 10 & $14-15,9$ & 0 & 0 & $0-19$ & 5 & 17 \\
\hline $16-17,9$ & 1 & 3 & $20-39$ & 15 & 50 & $16-17,9$ & 3 & 10 & $20-39$ & 6 & 20 \\
\hline $18-19,9$ & 10 & 33 & $40-59$ & 5 & 17 & $18-19,9$ & 13 & 43 & $40-59$ & 9 & 30 \\
\hline $20-21,9$ & 14 & 47 & $60-79$ & 4 & 14 & $20-21,9$ & 11 & 37 & $60-79$ & 7 & 24 \\
\hline $22-23,9$ & 5 & 17 & $80-99$ & 1 & 3 & $22-23,9$ & 2 & 7 & $80-99$ & 0 & 0 \\
\hline \multirow[t]{3}{*}{$24-25,9$} & \multirow[t]{3}{*}{0} & \multirow[t]{3}{*}{0} & $100-119$ & 0 & 0 & \multirow[t]{3}{*}{$24-25,9$} & \multirow[t]{3}{*}{1} & \multirow[t]{3}{*}{3} & $100-119$ & 2 & 6 \\
\hline & & & $120-139$ & 0 & 0 & & & & $120-139$ & 1 & 3 \\
\hline & & & $140-159$ & 2 & 6 & & & & $140-159$ & 0 & 0 \\
\hline
\end{tabular}

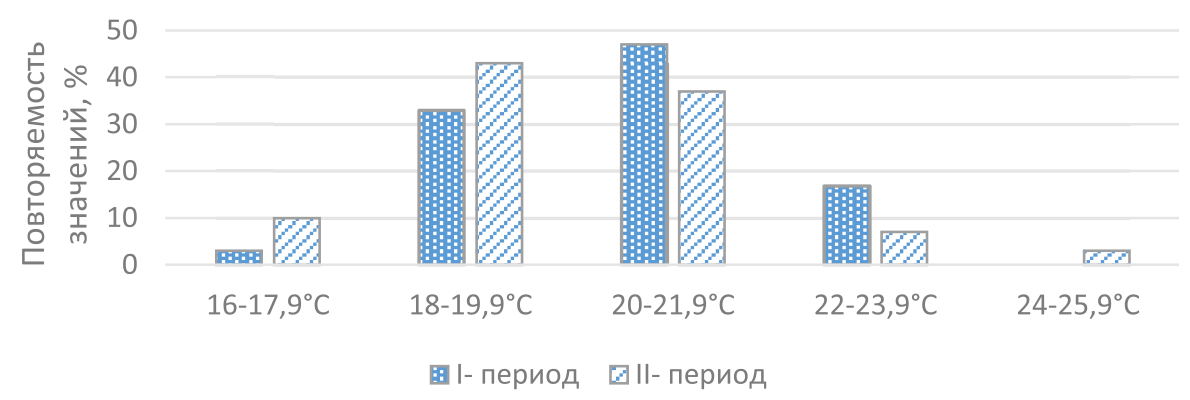

Рис. 2. Относительная повторяемость значений среднемесячной температуры воздуха июля на метеостанции «Атбасар» за I (1961-1990 г2.) и II (1991-2020 г2.) периоды
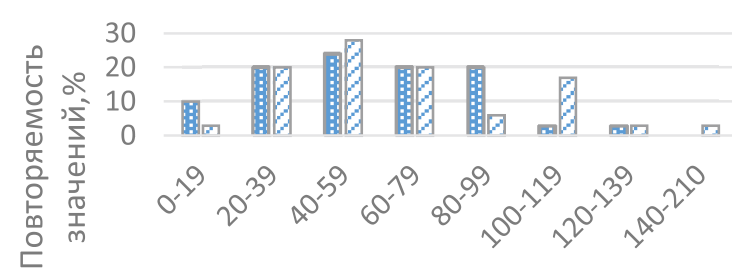

Осадки, мм

国I-период III-период

a)

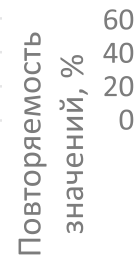

60
40
20
0

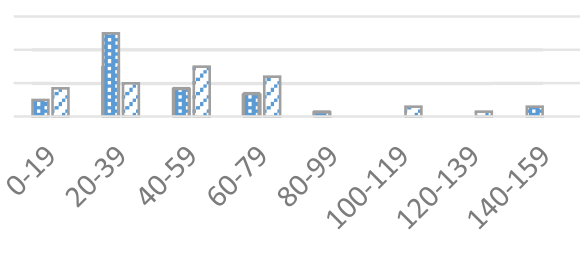

Осадки, мм

目I- период 团II-период

б)

Рис. 3. Относительная повторяемость значений среднемесячного количества осадков июля на метеостанцииях «Благовещенка» (а) и «Атбасар» (б) за I и II периоды 


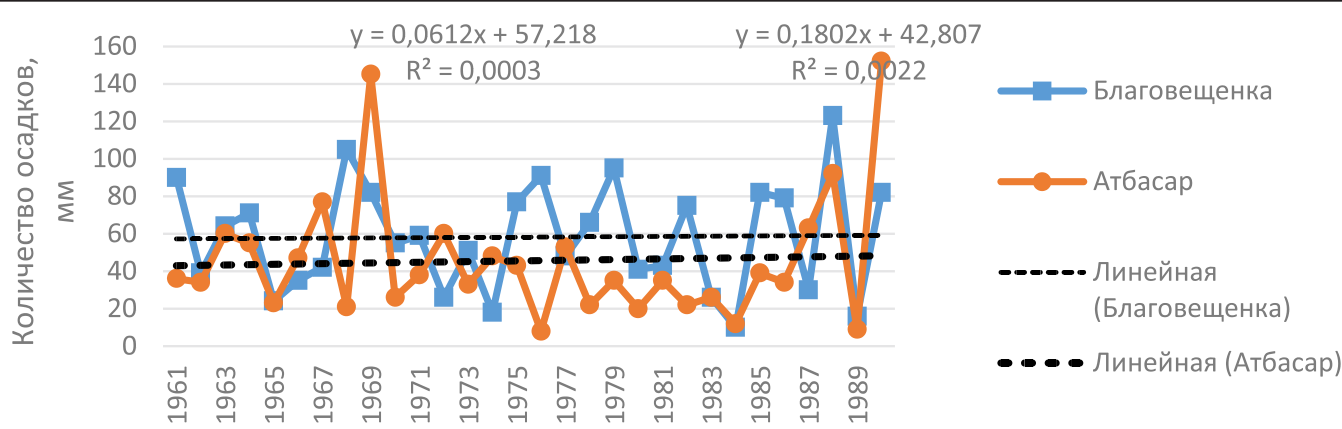

Рис. 4. Многолетняя динамика среднемесячного количества осадков июля за I период

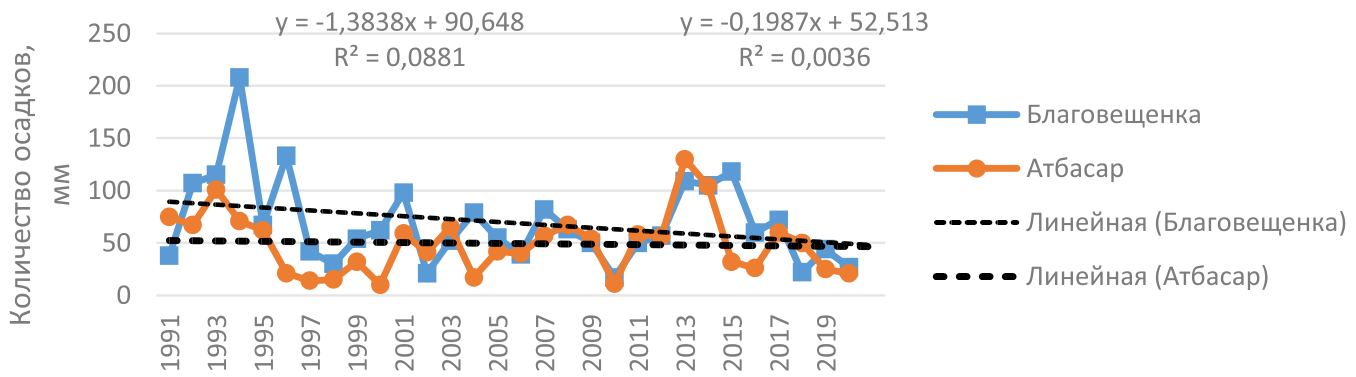

Рис. 5. Многолетняя динамика среднемесячного количества осадков июля за II период

В течение II периода (1991-2020 гг.) повторяемость значений среднемесячного количества осадков ниже нормы, в пределах 0-39 мм, встречается в 37\% исследованных лет; повторяемость значений среднемесячного количества осадков 40-59 мм, в пределах нормы, отмечается в $30 \%$; осадки, превышающие норму, в пределах 60-139 мм, выпали в $33 \%$ исследованных лет (рис. 3 , б).

На рис. 4 и 5 представлена многолетняя динамика среднемесячного количества осадков июля за I (1961-1990 гг.) и II периоды (1991-2020 гг.) на метеостанциях «Благовещенка» и «Атбасар».

В I периоде линия тренда имеет положительный наклон, что показывает тенденцию роста количества осадков на исследуемых метеостанциях (больше на метеостанции «Атбасар»). Во II периоде линия тренда для обеих метеостанций имеет отрицательный наклон, для метеостанции «Благовещенка» угол наклона и смещения больше, что характеризует динамику уменьшения среднемесячного количества осадков июля. На 2021 г. прогнозируется снижение осадков июля на обеих метеостанциях [4; 5].

\section{Выводы}

Таким образом, исходя из проведенного исследования, выявлено:

1. В I и во II периоде на метеостанции «Благовещенка» наибольшую повторяе- мость имеет значение температуры воздуха в пределах $18-19,9^{\circ} \mathrm{C}$, соответствующее многолетней норме. По сравнению с I периодом во II периоде повторяемость часто встречающихся значений среднемесячной температуры воздуха июля в пределах 18$19,9^{\circ} \mathrm{C}$ увеличилась на $6 \%$.

2. Наибольшую повторяемость на метеостанции «Атбасар» в течение I периода (1961-1990 гг.) имеет среднемесячное значение температуры воздуха июля $20-21,9^{\circ} \mathrm{C}$, соответствующее многолетней норме. Во II периоде (1991-2020 гг.) наибольшую повторяемость имеет среднемесячное значение температуры воздуха июля, которое на $1-2{ }^{\circ} \mathrm{C}$ ниже многолетней нормы.

3. В I периоде (1961-1990 гг.) на метеостанции «Благовещенка» повторяемость значений среднемесячного количества осадков ниже нормы встречается в $30 \%$ исследованных лет, в пределах нормы отмечается в $24 \%$, превышение нормы в $46 \%$. В течение II периода (1991-2020 гг.) повторяемость значений среднемесячного количества осадков ниже нормы встречается в $23 \%$ исследованных лет, в пределах нормы отмечается в $28 \%$, осадки, превышающие норму - в 49\%. По сравнению с I периодом во II периоде повторяемость засушливых лет уменьшилась на 7\%.

4. В течение I периода (1961-1990 гг.) на метеостанции «Атбасар» повторяемость 
значений среднемесячного количества осадков ниже нормы встречается в $60 \%$ исследованных лет, в пределах нормы отмечается в $17 \%$, осадки, превышающие норму в $23 \%$. В течение II периода (1991-2020 гг.) повторяемость значений среднемесячного количества осадков ниже нормы встречается в $37 \%$ исследованных лет, в пределах нормы отмечается в $30 \%$, осадки, превышающие норму - в $33 \%$. На данной метеостанции во II периоде по сравнению c I периодом повторяемость засушливых лет уменьшилась на $23 \%$.

5. Многолетняя динамика среднемесячного количества осадков июля за I период на двух метеостанциях характеризуется небольшим положительным наклоном линии тренда, что показывает тенденцию роста (больше на метеостанции «Атбасар»), а во II периоде отмечается уменьшение среднемесячного количества осадков июля. Прогноз на 2021 г. представлен снижением осадков июля на обеих метеостанциях.

\section{Список литературы / References}

1. Белоненко Г.В., Тусупбеков Ж.А., Ряполова Н.Л. Формирование и особенности влаго- и теплообмена ландшафтных провинций Западно-Сибирской равнины // Проблемы региональной экологии. 2015. № 3. С. 174-179.

Belonenko G.V., Tusupbekov Zh.A., Ryapolova N.L. Formation and features of water and heat exchange in landscape provinces of the West Siberian plain // Problemy regional'noj ekologii. 2015. No. 3. P. 174-179 (in Russian).

2. Метеорологический информационный сайт ФГБУ «ВНИИГМИ-МШД». Обнинск. 2020. [Электронный реcypc]. URL: http://meteo.ru/data/162-temperature-precipitation (дата обращения: 14.11.2020).

Meteorological information site of the Federal state budgetary institution «VNIIGMI-MCD». Obninsk. 2020. [Electronic resource]. URL: http://meteo.ru/data/162-temperature-precipitation (address date: 14.11.2020) (in Russian).

3. Кусаинова А.А., Мезенцева О.В. Влияние пространственной изменчивости температуры воздуха в начале вегетационного периода на формирование стока и испарения на территории Казахстана и на юге Западной Сибири // Астраханский вестник экологического образования. 2019. № 4 (52). C. $60-65$.

Kusainova A.A., Mezentseva O.V. The influence of spatial variability in air temperature at the beginning of the growing season on the formation of runoff and evaporation in Kazakhstan and in the south of Western Siberia // Astrahanskij vestnik ekologicheskogo obrazovaniya. 2019. No. 4 (52). P. 6065 (in Russian).

4. Паромов В.В., Земцов В.А., Копысов С.Г. Климат Западной Сибири в фазу замедления потепления (19862015 гг.) и прогнозирование гидроклиматических ресурсов на 2021-2030 гг. // Известия томского политехнического университета. инжиниринг георесурсов. 2017. Т. 328. № 1. C. 62-74.

Paromov V.V., Zemtsov V.A., Kopysov S.G. Climate of Western Siberia in the phase of slowing warming (1986-2015) and forecasting of hydro-climatic resources for 2021-2030 // Izvestiya tomskogo politekhnicheskogo universiteta. inzhiniring georesursov. 2017. V. 328. No. 1. P. 62-74. (in Russian).

5. Карнацевич И.В. Статистические прогнозы фазовонеоднородных метеорологических экстремумов // Омский научный вестник. 2008. № 2 (71). С. 62-65.

Karnatsevich I.V. Statistical forecasts of phase-inhomogeneous meteorological extremes // Omskij nauchnyj vestnik. 2008. No. 2 (71). P. $62-65$ (in Russian). 